\title{
Lifetime and Fluorescence Quantum Yield of Uranium(VI) Species in Hydrolyzed Solutions
}

\author{
Günther Meinrath $^{1,3}$, Stefan Lis $^{1}$, Zdzislaw Stryla $^{1}$ and Chicgua Noubactep ${ }^{3}$ \\ RER Consultants Passau \\ Adam-Mickiewicz-University Poznan \\ TU Bergakademie Freiberg
}

\section{Corresponding address:}

Dr. G. Meinrath

RER Consultants

Schießstattweg 3a

D-94032 Passau

Germany

Tel.: $\quad+4985170372$

FAX: $\quad+4985170372$

e-mail: meinrath@passau.baynet.de meinra01@fsrz1.rz.uni-passau.de meinrath@geo.tu-freiberg.de 


\title{
Lifetime and Fluorescence Quantum Yield of Uranium(VI) Species in
}

\section{Hydrolyzed Solutions}

\author{
by Günther Meinrath*1,2,5), Stefan Lis ${ }^{3)}$, Zdzislaw Stryla ${ }^{4)}$ and Chicgua Noubactep ${ }^{5)}$ \\ $1^{*}$ ) RER Consultants, Schießstattweg 3a, 94032 Passau, Germany \\ 2) Institute of Inorganic Chemistry, TU Bergakademie Freiberg, 09596 Freiberg, Germany \\ 3) Department of Rare Earths, Faculty of Chemistry, A.-Mickiewizc-University, 60780 Poznan, Poland \\ 4) Quantum Electronics Laboratory, Institute of Physics, A.-Mickiewicz-University, 60780, Poznan, Poland \\ 5) Institute of Geology, TU Bergakademie Freiberg, 09596 Freiberg, Germany
}

Key Words: uranyl(VI) hydrolysis, time-resolved laser-induced fluorescence spectroscopy, speciation, relative fluorescence yield

\begin{abstract}
:
Fluorescence lifetimes and emission intensities of uranium(VI) species $\mathrm{UO}_{2}{ }^{2+}$, $\left(\mathrm{UO}_{2}\right)_{2}(\mathrm{OH})_{2}{ }^{2+}$ and $\left(\mathrm{UO}_{2}\right)_{3} \mathrm{O}(\mathrm{OH})_{3}{ }^{+}\left(=\left(\mathrm{UO}_{2}\right)_{3}(\mathrm{OH})_{5}{ }^{+}\right)$are determined after excitation by a dye laser at $420 \mathrm{~nm}$. Despite the widely varying species concentrations in the different solutions, single-exponential decay with emission lifetimes between $2 \mu$ s and $15.5 \mu$ s has been observed, continuously varying with solution composition. Solution composition has been assessed by interpreting UV-Vis absorption spectra in the range $340 \mathrm{~nm}$ to $580 \mathrm{~nm}$ by available single component spectra. Factor analysis is used to assess the number of absorbing species in solution. Relative fluorescence quantum yields $12 \pm 3$ and $10 \pm 3$ times higher than for $\mathrm{UO}_{2}{ }^{2+}$ have been found for the $\left(\mathrm{UO}_{2}\right)_{2}(\mathrm{OH})_{2}{ }^{2+}$ and $\left(\mathrm{UO}_{2}\right)_{3} \mathrm{O}(\mathrm{OH})_{3}{ }^{+}$ species.
\end{abstract}

\section{Introduction}

Uranium in its hexavalent state is the only fluorescent actinide whose luminescence can be studied without often prohibitive precautions against radiation effects. Abundance of uranium in natural waters is reported at concentration levels between $0.1 \mathrm{ppb}$ to $40 \mathrm{ppb}$ [1], mostly in its hexavalent redox state. These concentrations are principially sufficient for 
direct fluorescence detection of uranium(VI) in natural aqueous systems. Despite recent progresses of understanding of some fundamental aspects of U(VI) fluorescence [2-5], it is far away from being a developped field. Chemistry of uranium has been -and probably still is- seen almost exclusively under its strategic aspects, thus neglecting many aspects of general interest. Among those aspects, the fluorescence lifetime of U(VI) in aqueous solutions has to be mentioned. Fluorescence lifetimes depend on temperature [6], presence of quenchers [4,7], speciation [8-10] and ionic strength [11,12]. These dependencies, however, remain to be understood in detail [12]. Fluorescence lifetime of U(VI) e.g. depends also on the concentration of acids, e.g. sulfuric and perchloric acid. The effect of perchloric acid, however, seems to be as pronounced as is the effect of sulfuric acid despite of the fact that perchloric acid certainly will not coordinate to $U(V I)$ to an extent comparable to sulfuric acid $[11,12]$.

A more profund understanding of these points requires availability of a wide range of experimental observations. Concerning U(VI) fluorescence, often only a very limited amount of experimental facts are available and the range of conditions studied is limited, too. In this work, 13 well-characterized hydrolyzed U(VI) solutions at elevated concentrations $\left(2 \cdot 10^{-4} \mathrm{M}\right.$ to $\left.2.1 \cdot 10^{-3} \mathrm{M} \mathrm{U}(\mathrm{VI})\right)$ in perchlorate medium were studied by quantitative UV-Vis absorption spectroscopy and lifetime measurements. These data extend previous studies of U(VI) fluorescence at lower concentrations [8,11].

\section{Experimental}

Uranium(VI) solutions were prepared from a stock solutions. The stock solution was prepared by dissolution of $\mathrm{UO}_{3} \cdot 2 \mathrm{H}_{2} \mathrm{O}$ in $0.1 \mathrm{M}$ perchloric acid. Changes in $\mathrm{pH}$ were made by addition of $0.1 \mathrm{M} \mathrm{NaOH}$ stock solution. A pH range from $\mathrm{pH} 3$ to $\mathrm{pH} 4.5$ and an uranium concentration range $2 \cdot 10^{-4} \mathrm{M}$ to $2.1 \cdot 10^{-3} \mathrm{M}$ are studied. In this region, $\mathrm{U}(\mathrm{VI})$ oligomers form but precipitation of a solid phase is prevented. The solutions were allowed 
to equilibrate for one week in equilibrium with air. UV-Vis absorption spectra were collected in digital form by double beam UV-Vis spectrometer (Shimadzu UV-2401PC) and processed by programs written by the authors. Noise reduction was achieved by averaging multiple scans. Interpretation of these spectra by factor analysis [13] suggested three species, in agreement with previous results $[13,14]$. Single component spectra of $\mathrm{UO}_{2}{ }^{2+},\left(\mathrm{UO}_{2}\right)_{2}(\mathrm{OH})_{2}{ }^{2+}$ and $\left(\mathrm{UO}_{2}\right)_{3} \mathrm{O}(\mathrm{OH})_{3}{ }^{+}$were taken from previous work $[13,15]$ and used without further processing. Statistical parameters were obtained from Spendley's quadratic approximation approach [16]. Within the validity of Beer's Law, the model function to interpret the observed absorption values is linear and, hence, confidence regions for solution compositions are exact (in the statistical sense). However, high correlation coefficients $\mathrm{c}$ of the single component spectra with $\mathrm{c}\left(\left(\mathrm{UO}_{2}\right)_{2}(\mathrm{OH})_{2}{ }^{2+}\right.$, $\left.\left(\mathrm{UO}_{2}\right)_{3} \mathrm{O}(\mathrm{OH})_{3}{ }^{+}\right)$as large as -0.951 have been observed. This high correlation is a property inherent in the system under study and can not be resolved. Relevance of the numerical results have been estimated by the consistency of experimentally and analytically obtained total U(VI) concentrations.

Lifetimes are measured after excitation with a dye-laser pulse at $420 \mathrm{~nm}$. Laser pulse energy was about $100 \mu \mathrm{J}$. The laser system, the miniaturized dye laser and the detection system are home-made by one of the auhors (Z.S.). Temperature has been $(22 \pm 1)^{\circ} \mathrm{C}$.

\section{Results and Discussion}

The spectra included into the study are given in Fig. 1 . The properties of the 13 spectra are investigated by abstract factor analysis (AFA) $[13-15,17]$ with some results summarized in Table 1. AFA is a model-free technique that allows inference into UV-Vis absorption data without a priori assumptions and is recently applied to hydrolyzed U(VI) solutions [13$15,18,19]$. Main advantage of factor analysis techniques is the model-free approach and strong commitment to statistical criteria. In the present context, AFA is used to assess the number of factors (species) contributing significantly to the observed absorption spectra. 
Included into the first column of Table 1 are the eigenvalues of the data matrix $\mathrm{A}$ consisting of 13 column vectors, each holding an experimental spectrum of a one of the 13 U(VI) solutions. Eigenvectors and eigenvalues are extracted from that data matrix by the Singular Value Decomposition. More details on the application of factor analysis techniques to U(VI) spectral analysis are given in [13-15] and will not be repeated here. The second column gives the result of a $\chi^{2}$ test together with the critical values in the third column. A factor is considered significant if the $\chi^{2}$ value is larger than its critical value. Hence, the $\chi^{2}$ test suggests three factors. The fourth column holds the so-called real error in the data matrix, RE. The real error accepts a factor if the corresponding RE value is larger than the average noise and background effect in the spectral data. For two factors, $\mathrm{RE}$ is $7.7 \cdot 10^{-4}$ which is larger than the noise of the spectrometer, while the value of $3 \cdot 10^{-4}$ for the third factor would be a rather optimistic estimate for the spectrometer's noise level. The SCREE test, giving the residual percent variance in the data matrix as a function of the number of significant factors is given in Fig. 2. As observed previously, the first factor carries about $99 \%$ of the data variance [15] due to the strong overlap of the spectra (cf. Fig. 1) as is also indicated by the high off-diagonal values of the correlation matrix. The SCREE test levels out at three factors, again the third factor is uncertain.

A typical example for a resolved UV-Vis spectrum is given in fig. 3. In order to get information on the fluorescence intensity contribution of a species, an estimate of the absorption value of the species in a multicomponent mixture is required [20]:

$$
\mathrm{I}_{\mathrm{f}, \theta}=\mathrm{I}_{0} \cdot \phi_{\mathrm{f}} \cdot 2.302 \cdot \varepsilon_{\lambda} \cdot \mathrm{c} \cdot \mathrm{d}
$$

with

$\mathrm{I}_{\mathrm{f}, \theta}$ : fluorescence intensity at wavelength $\theta$

$I_{0}$ : intensity of the excitation source

$\phi_{\mathrm{f}}$ : fluorescence quantum yield 
$\varepsilon_{\lambda}$ : decadic molar absorption at excitation wavelength $\lambda$

$\mathrm{d}$ : path length in $\mathrm{cm}$

From the absorption values of the individual species at $420 \mathrm{~nm}$, the relative absorption values can be estimated. Assuming the source intensity to be constant in the time average and the fluorescence quantum yield equal for each species, relative fluorescence intensities for each species can be obtained within the limits of the precision in each step of the total analysis.

In principal, the fluorescence contributions of each species may be estimated from the lifetime curves, if the lifetimes of the species are sufficiently different and the lifetime of a species is larger than that of the electronically excited state. This behaviour has been observed previously $[8,11]$ in solutions taken from $\mathrm{U}(\mathrm{VI})$ solid-aqueous phase equilibria. In the present case, however, only a single-exponential decay has been observed with lifetimes varying with the absorption ratio of the individual species. This observation can be understood that the electronically excited state has a longer lifetime than the species itself. Hence, an excited U(VI) electron may be transform into a different species before electronic relaxation occurs.

In Fig. 4, decay curves for two solutions are given. The analytical data of these solutions are given in Table 2. In all 13 cases, single-exponential decay has been observed. Fig. 5a gives the dependence of observed fluorescence lifetime as a function of the absorption ratio $r_{1}$ with $r_{1}$ defined as

$$
\mathrm{r}_{1}=\varepsilon_{10} / \varepsilon_{22}
$$

$\varepsilon_{10}$ : decadic molar absorption of $\mathrm{UO}_{2}{ }^{2+}$ at $420 \mathrm{~nm}$

$\varepsilon_{22}$ : decadic molar absorption of $\left(\mathrm{UO}_{2}\right)_{2}(\mathrm{OH})_{2}{ }^{2+}$ at $420 \mathrm{~nm}$.

From Fig.5a the overwhelming fluorescence intensity of $\left(\mathrm{UO}_{2}\right)_{2}(\mathrm{OH})_{2}{ }^{2+}$ compared to $\mathrm{UO}_{2}{ }^{2+}$ is evident. The characteristic lifetime of the $\mathrm{UO}_{2}{ }^{2+}$ species of about $2 \mu$ s increases 
already on the presence of $10 \%\left(\mathrm{UO}_{2}\right)_{2}(\mathrm{OH})_{2}{ }^{2+}$ species. This is a relative concentration at the edge of detectability by the UV-Vis absorption method. In Fig. 5b, the dependence of observed fluorescence lifetimes is given as a function of absorption ratio $r_{2}$ defined as

$$
\mathrm{r}_{2}=\varepsilon_{22} / \varepsilon_{35}
$$

$\varepsilon_{35}$ : decadic molar absorption of $\left(\mathrm{UO}_{2}\right)_{3} \mathrm{O}(\mathrm{OH})_{3}{ }^{+}$at $420 \mathrm{~nm}$.

The relative fluorescence intensity ratio between $\left(\mathrm{UO}_{2}\right)_{2}(\mathrm{OH})_{2}{ }^{2+}$ and $\left(\mathrm{UO}_{2}\right)_{3} \mathrm{O}(\mathrm{OH})_{3}{ }^{+}$is more balanced and the phenomenological lifetime of the $\left(\mathrm{UO}_{2}\right)_{2}(\mathrm{OH})_{2}{ }^{2+}$ species of about 7$9 \mu$ increases at absorption ratios $r_{2}$ of about 1 .

These findings are discrepant with previous observations where a double-exponential decay has been observed between the $\mathrm{UO}_{2}{ }^{2+} /\left(\mathrm{UO}_{2}\right)_{2}(\mathrm{OH})_{2}{ }^{2+}$ species, $\left(\mathrm{UO}_{2}\right)_{2}(\mathrm{OH})_{2}{ }^{2+} /\left(\mathrm{UO}_{2}\right)_{3} \mathrm{O}(\mathrm{OH})_{3}{ }^{+}$species and $\left(\mathrm{UO}_{2}\right)_{3} \mathrm{O}(\mathrm{OH})_{3}{ }^{+} / \mathrm{UO}_{2} \mathrm{CO}_{3}{ }^{\circ}$ species [9,11]. From the previous work, single component emission spectra of the respective species are evaluated and validated by spectral resolution of multicomponent emission spectra and the Stokes relationship between absorption and emission spectra of each species [5]. The lifetimes given there for $\mathrm{UO}_{2}{ }^{2+},\left(\mathrm{UO}_{2}\right)_{2}(\mathrm{OH})_{2}{ }^{2+}$ and $\left(\mathrm{UO}_{2}\right)_{3} \mathrm{O}(\mathrm{OH})_{3}{ }^{+}$are $(0.9 \pm 0.3) \mu \mathrm{s}$, $(2.9 \pm 0.4) \mu$ s and $(7 \pm 1) \mu$ s [11]. The previous observation is also in agreement with ${ }^{17} \mathrm{O}$ NMR studies [8] for the $\mathrm{UO}_{2}{ }^{2+} /\left(\mathrm{UO}_{2}\right)_{2}(\mathrm{OH})_{2}{ }^{2+}$ equilibrium. In the range, where $\left(\mathrm{UO}_{2}\right)_{2}(\mathrm{OH})_{2}{ }^{2+}$ seems to govern the fluorescence emission, however, phenomenological fluorescence lifetimes in the range 7 - $9 \mu$ s have been found, much larger than about $2 \mu \mathrm{s}$ given previously $[9,11,21]$. The difference in the excitation wavelength (266 nm [11] compared to $420 \mathrm{~nm}$ ) is unlikely to be a possible reason for the observed differences. The lifetimes of uranium(VI) in aqueous solutions do not lend itself to an easy interpretation and several aspects are not yet understood [5,12]. It seems, however, that the kinetics of the species formation and dissociation depends on solution composition and/or some 
catalysis of the exchange rate that has not been realized previously due to the very limited amount of experimental studies in the $\mathrm{U}(\mathrm{VI})-\mathrm{H}_{2} \mathrm{O}-\mathrm{CO}_{2}$ fluorescence system.

The time traces of the electronic decay carry the information on the number of excited states generated by the laser pulse. For the present system, pulse duration is about 5 ns, much shorter than the decay rate. Hence, the excitation pulse may be considered as instantaneous and all electronically excited states may be considered to be created at a time $t_{0}$. The relative number of excited states may be estimated from the time traces by extrapolating the fitted decay curve to $\mathrm{t}=\mathrm{t}_{\mathrm{o}}$.

By adapting eq. 1 to a three-component system and defining the quantity $\mathrm{k}_{\mathrm{xy}}=\left(\mathrm{I}_{0} 2.303\right.$ $\varepsilon_{\mathrm{xy}} \mathrm{C}_{\mathrm{xy}} \mathrm{d}$ ) -where $\mathrm{xy}$ is either 11,22 or 35 - a quantity $\mathrm{Q}$ is obtained from numerical interpretation of the UV-Vis absorption spectra in eq. 4:

$$
\mathrm{Q}=\int_{\mathrm{I}_{\phi, \pi}}=\mathrm{k}_{10} * \phi_{\mathrm{f}, 10}+\mathrm{k}_{22} * \phi_{\mathrm{f}, 22}+\mathrm{k}_{35} * \phi_{\mathrm{f}, 35}
$$

Q gives a measure of the relative fluorescence quantum yield of $\mathrm{UO}_{2}{ }^{2+},\left(\mathrm{UO}_{2}\right)_{2}(\mathrm{OH})_{2}{ }^{2+}$ and $\left(\mathrm{UO}_{2}\right)_{3} \mathrm{O}(\mathrm{OH})_{3}{ }^{+}$species by collecting the emission over all emission wavelengths. Subscript $\pi$ indicates that the photons are collected at the photomultiplier tube under a very limited range of angles, $\phi_{\mathrm{f}, \mathrm{xy}}$ represents the relative fluorescence quantum yield and xy is representing the respective absorbing species. Only the relative magnitude of $\phi_{\mathrm{f}, \mathrm{xy}}$ is meaningful.

The numerical interpretation of the data resulted in relative fluorescence yields $\phi_{\mathrm{f}, 22}=12$ \pm 3 of $\left(\mathrm{UO}_{2}\right)_{2}(\mathrm{OH})_{2}{ }^{2+}$ and $\phi_{\mathrm{f}, 35}=10 \pm 3$, while the fluorescence quantum yield of $\mathrm{UO}_{2}{ }^{2+}$ is $\phi_{\mathrm{f}, 10},=1$. The uncertainties are obtained from a Jackknife analysis that give a $68 \%$ confidence region, corrected for the small sample size by appropriate Student's t. The result shows that $\mathrm{UO}_{2}{ }^{2+}$ is a poorly fluorescent ion. Formation of oligomeric hydrolysis species strongly increases the fluorescence quantum yield. In agreement with the interpretation of Figs. 5, small amounts of $\left(\mathrm{UO}_{2}\right)_{2}(\mathrm{OH})_{2}{ }^{2+}$ species are able to govern the 
fluorescence emission even if $\mathrm{UO}_{2}{ }^{2+}$ is the major solution species. The situation is different for $\left(\mathrm{UO}_{2}\right)_{2}(\mathrm{OH})_{2}{ }^{2+}$ and $\left(\mathrm{UO}_{2}\right)_{3} \mathrm{O}(\mathrm{OH})_{3}{ }^{+}$where the difference in the relative quantum yield is hardly significant and the increase in the fluorescence lifetime occurs roughly at $\mathrm{r}_{2} \approx 1$.

There is, at present, only one other study reporting relative fluorescence efficiencies [22]. The both studies however can not be compared. The solution compositions in the other study are not assessed by direct spectroscopic speciation but inferred from numerical calculation. In that calculations, formation constants from a data base [23] have been used. It has been shown previously that these formation constants are not in agreement with similar other assessments of $\mathrm{U}(\mathrm{VI})$ hydrolytic behaviour and also discrepant with direct speciation by using UV-Vis and laser-induced fluorescence spectroscopy $[13-15,18,19,26]$.

\section{Conclusions}

The lifetime behaviour of $\mathrm{U}(\mathrm{VI})$ species $\mathrm{UO}_{2}{ }^{2+},\left(\mathrm{UO}_{2}\right)_{2}(\mathrm{OH})_{2}{ }^{2+}$ and $\left(\mathrm{UO}_{2}\right)_{3} \mathrm{O}(\mathrm{OH})_{3}{ }^{+}$has been investigated by quantitative methods. In disagreement with previous results, concentration-dependent lifetimes have been observed. At the present state of our understanding of the U(VI) fluorescence decay, no explanation for these discrepancies is available. The observed lifetimes are $\lambda_{10}=(2 \pm 0.5) \mu \mathrm{s}, \lambda_{22}=(8 \pm 1) \mu \mathrm{s}$ and $\lambda_{35} \geq 15 \mu \mathrm{s}$. From a quantitative interpretation of the absorption spectra of the solutions studied, absorption values of the respective species at the excitation wavelength are obtained. Thus, the relative fluorescence yields of $\left(\mathrm{UO}_{2}\right)_{2}(\mathrm{OH})_{2}{ }^{2+}$ and $\left(\mathrm{UO}_{2}\right)_{3} \mathrm{O}(\mathrm{OH})_{3}{ }^{+}$are determined as $\phi_{\mathrm{f}, 22}=$ $12 \pm 3$ and $\phi_{\mathrm{f}, 35}=10 \pm 3$, compared to $\phi_{\mathrm{f}, 10}=1$. Here is, however, a note of caution necessary: The relative quantum yields depend strongly on the quantum yield obtained for the $\mathrm{UO}_{2}{ }^{2+}$ species to which the relative values $\phi_{\mathrm{f}, 22}$ and $\phi_{\mathrm{f}, 35}$ are normalized. This value is small and has a comparatively high uncertainty. All experimental quantities are affected by a series of experimental uncertainties, starting with the spectral deconvolution of the multicomponent UV-Vis spectra, stability of the laser system, temporal stability of U(VI) 
solutions, e.g. absence of quenchers including organic material etc. The magnitudes of relative quantum yields are, however, in agreement with other experimental observations, as already mentioned above.

Direct speciation of sample solutions by suitable techniques like UV-Vis absorption spectroscopy is a necessary prerequisite for interpreting fluorescence emission spectra on a quantitative level. The data forwarded from present study seems to be internally consistent. Nevertheless, the error margins in the relative fluorescence yields are considerable. These margins are to a large part due to the rather imbalanced properties of the $\mathrm{UO}_{2}{ }^{2+} /\left(\mathrm{UO}_{2}\right)_{2}(\mathrm{OH})_{2}{ }^{2+} /\left(\mathrm{UO}_{2}\right)_{3} \mathrm{O}(\mathrm{OH})_{3}{ }^{+}$system. The both oligomeric species have high molar absorption values compared to $\mathrm{UO}_{2}{ }^{2+}$ and show a strong fluorescence contribution at relative low concentrations.

\section{References}

1 Rogers, J.J.W., Adams, J.A.S.; "Uranium" in: Handbook of Geochemistry, Part II-2, Chpt. 92 BO, (1972)

2 Moriyasu, M., Yokoyama, Y., Ikeda, S.; J. Inorg. Nucl. Chem., $\underline{39}$ (1977), 2199-2203; Matsushima, R., Fujimori, H., Sakuraba, S.; J. Chem. Soc. Faraday Trans., 70 (1974), 1702

3 Moulin, Ch., Reiller, P., Beaucaire, C., Lemordant, D.; Appl. Spect., 4 77 (1993), 21722174

4 Moulin, Ch., Beaucaire, C., Decambox, P., Mauchien, P.; Anal. Chim. Acta, $\underline{238}$ (1990), 291

5 Meinrath, G., Kato, Y., Kimura, T., Yoshida, Z.; Radiochim. Acta, 82 (1998), 115-120

6 Formosinho, S.J., M.D.Graca, M.; J. Chem. Soc. Faraday Trans., $\underline{80}$ (1984), 1745-1756

7 Matsushima, R.; J. Am. Chem. Soc., $\underline{94}$ (1972), 6010-6016

8 Park, Y.Y., Sakai, Y., Abe, R., Ishii, T., Harada, M., Kojima, T., Tomiyasu, H.; J. Chem. Soc. Faraday Trans., 86 (1990), 55 
9 Meinrath, G., Kato, Y., Yoshida, Z.; J. Radioanal. Nucl. Chem., 174 (1993), 299-314

10 Moulin, C., Decambox, P., Moulin, V., Decaillon, J.G.; Anal. Chem., 67 (1995), 348 353

11 Kato, Y., Meinrath, G., Kimura, T., Yoshida, Z.; Radiochim. Acta, 64 (1994), 107-111

12 Bouby, M., Billard, I., Bonnenfant, A., Klein, G.; Chem. Phys, 240 (1999), 353-370

13 Meinrath, G.; Radiochim. Acta, 77 (1997), 221-234

14 Meinrath, G.; J. Alloy Comp., 275-277 (1998), 777-781

15 Meinrath, G., Schweinberger, M.; Radiochim. Acta, 75 (1996), 205-210

16 Spendley, W.; in: Optimization (R. Fletcher, ed.), Institute of Mathematics and Its Application, Academic Press, London/UK (1969), 259

17 Otto, M.; Chemometrics, Wiley-VCH, Weinheim/F.R.G. (1998)

18 Dai, S., Burleigh, M.C., Simonson, J.M., Mesmer, R.E., Xue, X.-L.; Radiochim. Acta, $\underline{81}$ (1998), 195-199

19 Lubal, P., Havel, J.; Chem. Papers, $\underline{51}$ (1997), 213-220

20 Perkampus, H.-H.; Encyclopedia of Spectroscopy, Wiley-VCH, Weinheim/F.R.G. (1995), 669p.

21 Azenha, M.E.D.G., Burrows, H.D., Formosinho, S.J., M.G.M.Miguel, Daramanyan, A.P., Khudyakov, I.V.; J. Luminescence, $\underline{48 / 49}$ (1991), 522-526

22 Eliet, V., Bidoglio, G., Omenetto, N., Parma, L., Grenthe, I.; J. Chem. Faraday Trans., $\underline{91}$ (1995), 2275-2285

23 Grenthe, I., Fuger, J., Konings, R., Muller, A.B., Nguyen-Trung, C., Wanner, H.; Chemical Thermodynamics of Uranium, OECD/NEA, Paris/France, (1992)

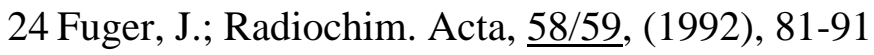

25 Fuger, J., Khodakhovskiy, I.L., Sergeyeva, E.J., Medvedev, V.A., Navratil, J.D.; The Chemical Thermodynamics of Actinide Elements and Compounds.-Part 12. The Actinide Inorganic Complexes, IAEA, Wien/Austria, (1992), 13-41 
26 Meinrath, G.; J. Radioanal. Nucl. Chem., 232 (1998), 179-188 
Table 1: Results of AFA for the first eight of 13 eigenvalues

\begin{tabular}{lccc}
\hline eigenvalue & $\chi^{2}$ & $\begin{array}{c}\text { critical values } \\
\text { of } \chi^{2}\end{array}$ & $\mathrm{RE}$ \\
8.2661422 & 116241 & 144 & $3.956 \cdot 10^{-3}$ \\
0.0464031 & 1132 & 121 & $7.694 \cdot 10^{-4}$ \\
0.0014725 & 127 & 100 & $2.928 \cdot 10^{-4}$ \\
0.0000872 & 10.3 & 81 & $2.247 \cdot 10^{-4}$ \\
0.0000208 & 2.5 & 64 & $1.314 \cdot 10^{-4}$ \\
0.0000059 & 1.3 & 49 & $9.552 \cdot 10^{-5}$ \\
0.0000043 & 0.7 & 36 & $8.332 \cdot 10^{-5}$ \\
0.0000028 & 0.43 & 25 & $7.253 \cdot 10^{-5}$ \\
\hline
\end{tabular}

$\mathrm{RE}$ : real error in the data matrix 
Table 2: analytical data of U(VI) solutions given in fig. 4

\begin{tabular}{ccc}
\hline lifetime & $7.8 \mu \mathrm{s}$ & $14.8 \mu \mathrm{s}$ \\
$\mathrm{pH}$ & 4.27 & 4.42 \\
{$\left[\mathrm{UO}_{2}{ }^{2+}\right]$} & $9.9 \cdot 10^{-4} \pm 1.0 \cdot 10^{-5}$ & $3.1 \cdot 10^{-4} \pm 2.31 \cdot 10^{-5}$ \\
{$\left[\left(\mathrm{UO}_{2}\right)_{2}(\mathrm{OH})_{2}{ }^{2+}\right]$} & $2.05 \cdot 10^{-4} \pm 1.7 \cdot 10^{-6}$ & $6.2 \cdot 10^{-5} \pm 2.8 \cdot 10^{-6}$ \\
{$\left[\left(\mathrm{UO}_{2}\right)_{3} \mathrm{O}(\mathrm{OH})_{3}{ }^{+}\right]$} & $4.8 \cdot 10^{-6} \pm 1.9 \cdot 10^{-7}$ & $2.9 \cdot 10^{-5} \pm 1.0 \cdot 10^{-6}$ \\
& & \\
\hline
\end{tabular}

[] : concentration; uncertainty in $\mathrm{pH}$ is \pm 0.03 (68 \% confidence limit)

\section{Figure Captions:}

Fig. 1: experimental UV-Vis spectra of hydrolyzed U(VI) solutions at different $\mathrm{pH}$ in the range $\mathrm{pH} 3$ to $\mathrm{pH} 4.5$ and uranium concentration range $2 \cdot 10^{-4} \mathrm{M}$ to $2.1 \cdot 10^{-3} \mathrm{M}$.

Fig. 2: residual percent variance as a function of factors (SCREE test)

Fig. 3: experimental UV-Vis absorption spectrum at $\mathrm{pH} 4.42$ and $5.2 \cdot 10^{-4} \mathrm{M} \mathrm{U}(\mathrm{VI})$. Numerical data is included into Table 2 
Fig. 4: time traces of fluorescence decay of hydrolyzed U(VI) solutions with composition given in Table 2.

Fig. 5a,b: Variation of fluorescence lifetimes as function of the ratio $r_{1}(a)$ and ratio $r_{2}(b)$ 


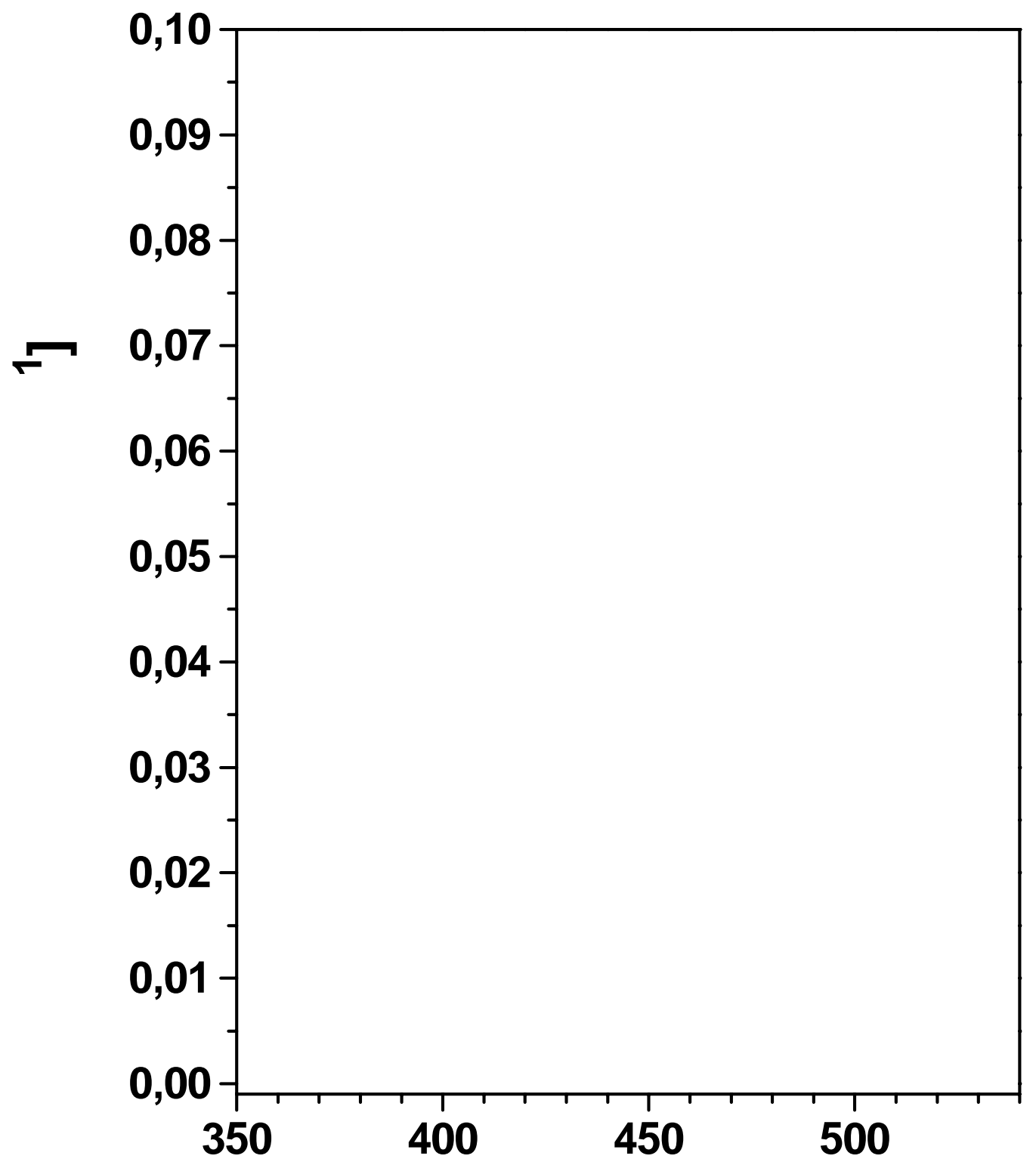




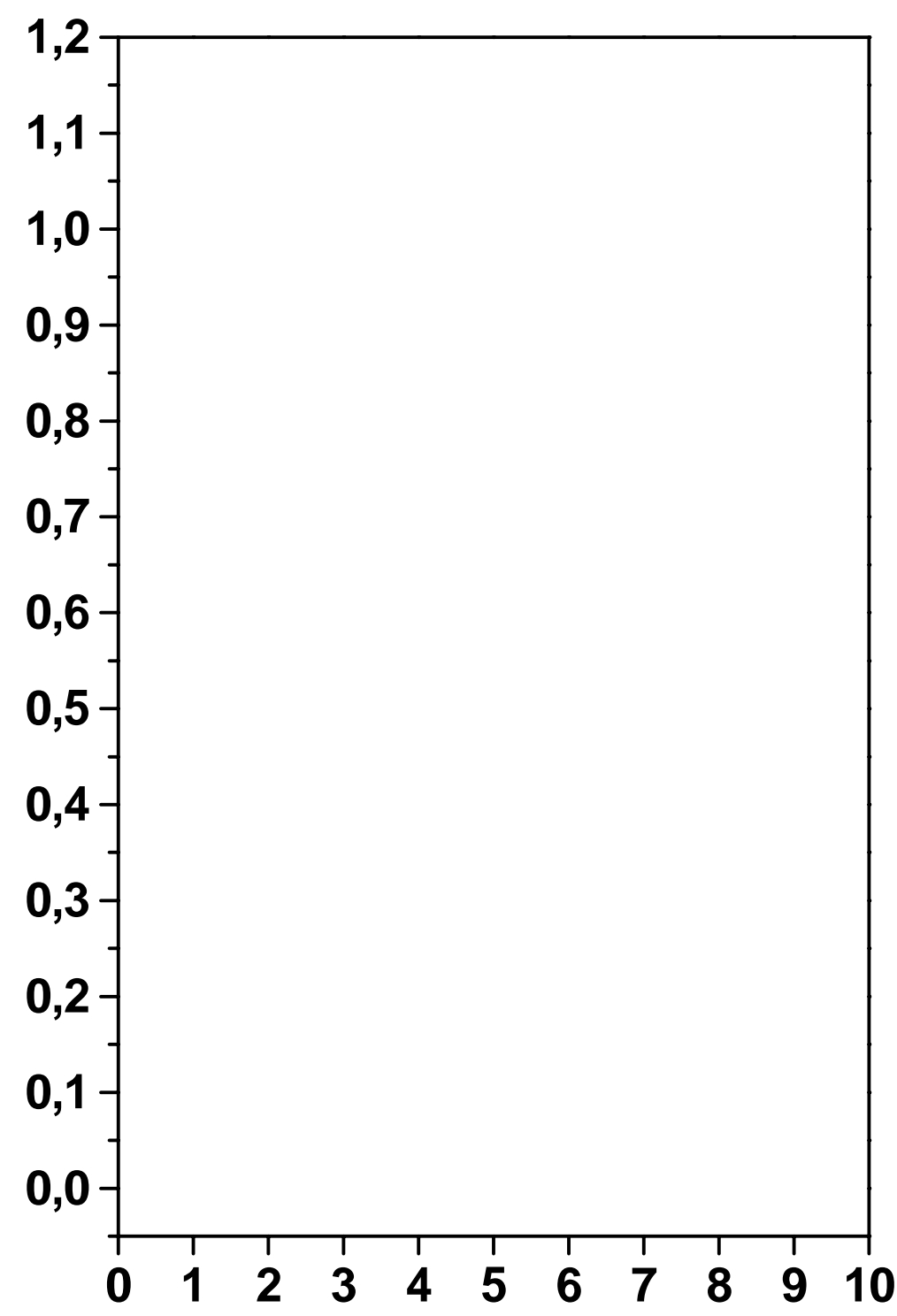




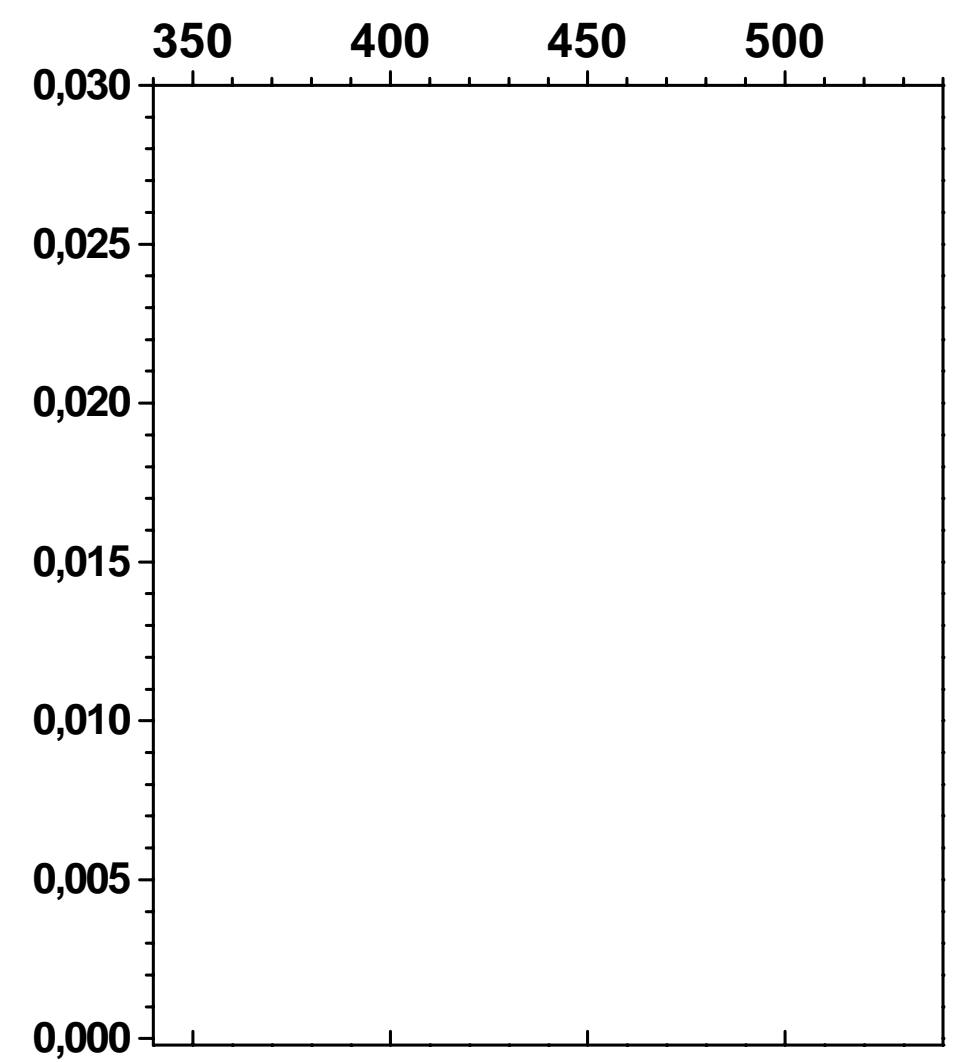




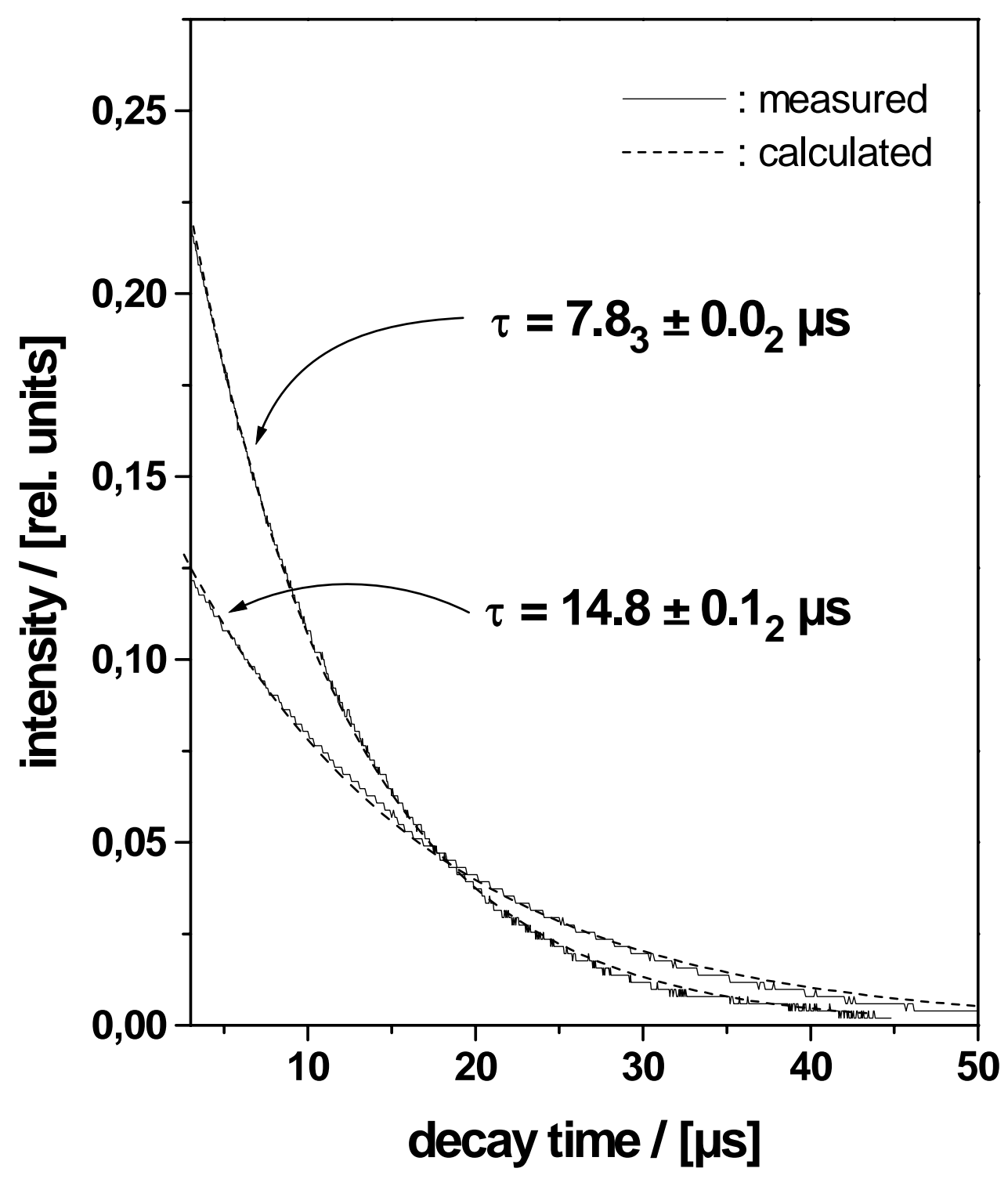

figure 4 


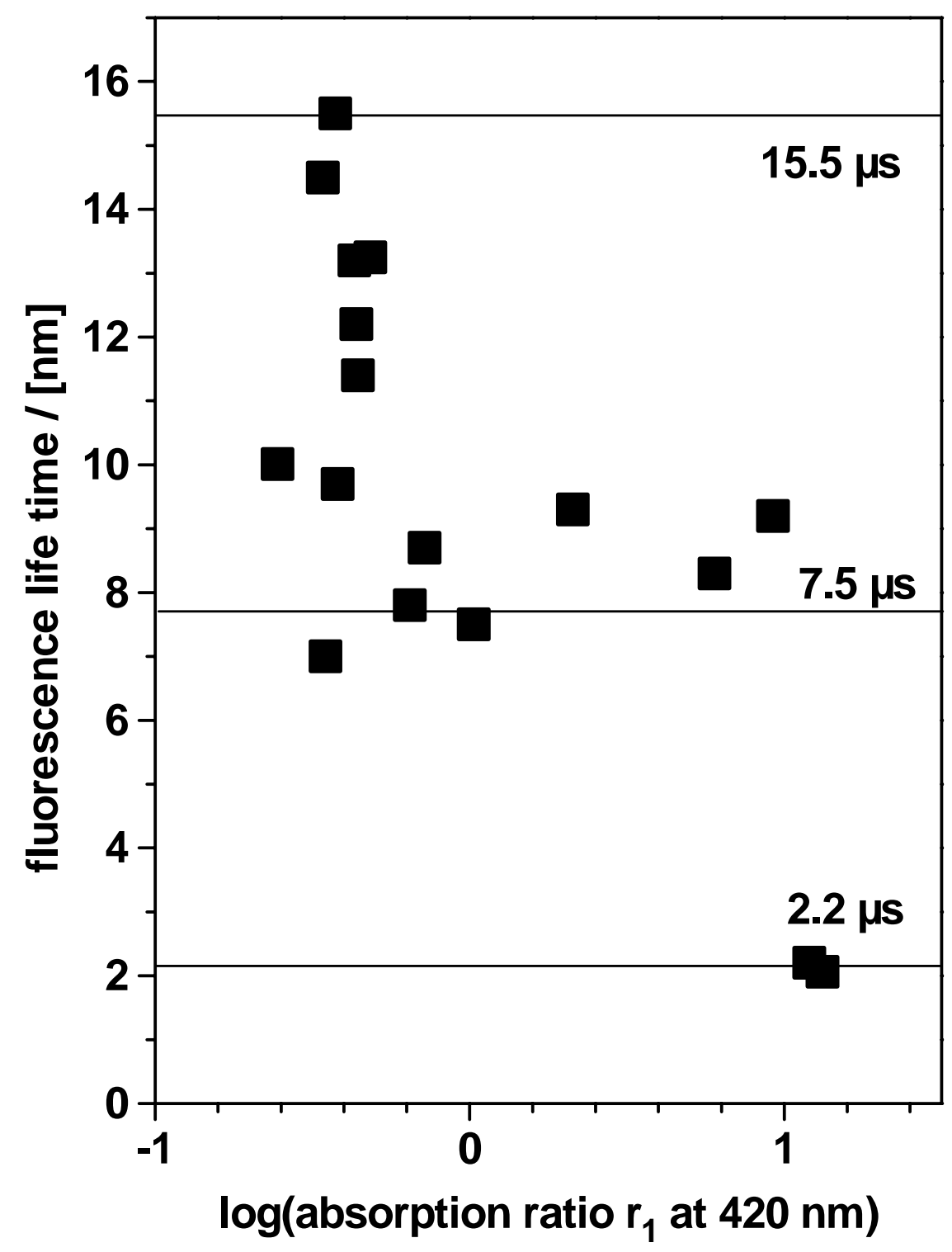

figure $5 a$ 


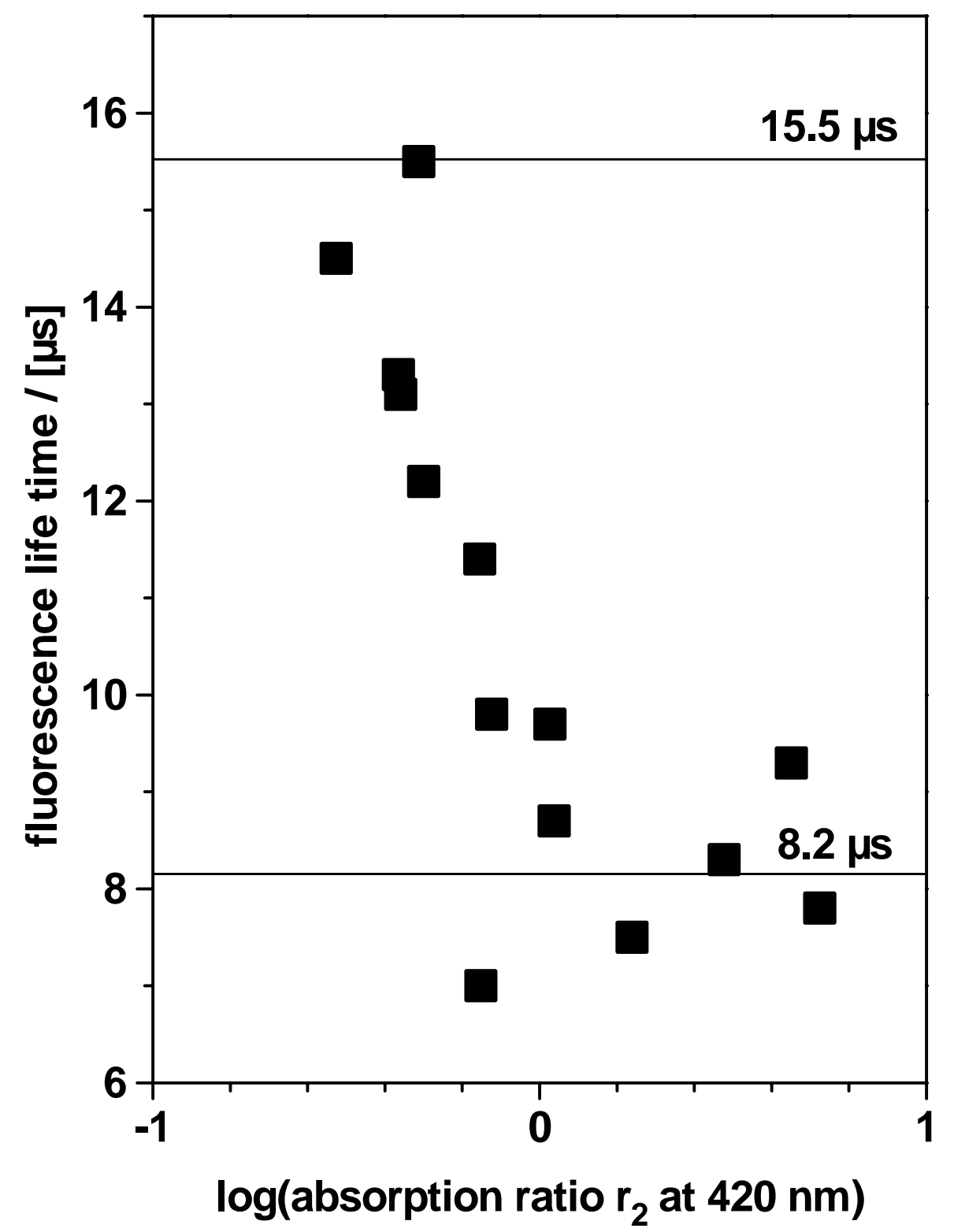

figure $5 a b$ 